\title{
NECROTIZING SIALOMETAPLASIA - A SELF LIMITING CONDITION WHICH POSES A DIAGNOSTIC DILEMMA
}

\author{
Abhishek Gupta ${ }^{1}$, Anamika Priyadarshinee ${ }^{2}$, LAVANYA RAO ${ }^{3}$, ANJU REDHU ${ }^{4}$, and \\ KUMARI JHA ${ }^{5}$ \\ ${ }^{1}$ KIST Medical College \\ ${ }^{2} \mathrm{KISTMCTH}$ \\ ${ }^{3}$ Aster CMI Hospital \\ ${ }^{4} \mathrm{PGIDS}$ \\ ${ }^{5}$ GDCRIB
}

November 20, 2020

\begin{abstract}
Necrotizing sialometaplasia is a salivary gland disease which is clinically as well as histologically quite confusing with a malignant squamous cell carcinoma. Presenting here a case of a male with Necrotizing sialometaplasia who was anxious because of cancerphobia as he was a smoker.
\end{abstract}

Title page:

TITLE: NECROTIZING SIALOMETAPLASIA - A SELF LIMITING CONDITION WHICH POSES A DIAGNOSTIC DILEMMA

Key words:Sialometaplasia, Necrotizing, Salivary Gland Diseases, Carcinoma, Squamous Cell, Oral ulcer

Key Clinical Message: Necrotizing Sialometaplasia can make anyone very anxious about the lesion especially if they have habit of tobacoo consumption. It requires a prompt diagnosis, counselling with assurance to patient and treatment.

\section{Authors Details:}

1. Abhishek Gupta, Lecturer, Incharge, Department of Oral Medicine and Radiology, KIST Medical College and Teaching hospital

2. Anamika Priyadarshinee, Lecturer, Department of Pathology, KIST Medical college and teaching hospital

3. Lavanya Nanjunda Rao Oral Physician and Maxillofacial Radiologist, Dental Unit, Aster CMI Hospital

4. Anju Redhu Senior Resident, Department of Oral Medicine and Radiology, PGIDS

5. Kumari Sonam Jha Post graduate Student, Department of Oral Medicine and Radiology, GDCRI.

\section{Corresponding author:}

Dr. Abhishek Gupta,

Lecturer, Incharge, Department of Oral Medicine and Radiology, KIST Medical College and Teaching hospital , Imadole, Lalitpur, Bagmati, Nepal, 44705

drabhishekgupta30373a@gmail.com 


\section{NECROTIZING SIALOMETAPLASIA - A SELF LIMITING CONDITION WHICH POSES A DIAGNOSTIC DILEMMA}

\section{INTRODUCTION:}

Necrotizing Sialometaplasia (NS) was first reported by Abrams et $\mathrm{al}^{1}$ in the year 1973, who had added this new clinical entity to the salivary gland pathology termed as "Necrotizing Sialometaplasia" which was the histological description of the lesion - as an inflammatory disease characterized by lobular necrosis by mucus escape reaction and by marked squamous metaplasia and pseudoepitheliomatous hyperplasia.This rare entity has been classified under inflammatory and reactive lesions of salivary gland diseases. ${ }^{2}$ This condition has been described as non-neoplastic inflammatory condition of the salivary glands ${ }^{2}$ and benign, self-limiting, reactive inflammatory disorder of salivary tissue. NS can resemble a malignancy and its misdiagnosis has resulted in unnecessary radical surgery. ${ }^{3}$ Mesa et al had reviewed approximately 10,000 oral biopsy specimens in the year 1984 and had revealed only three cases of necrotizing sialometaplasia, all of which had been misdiagnosed as other benign entities, representing only 0.03 percent of biopsied oral lesions. ${ }^{4}$ Shin et al. had reviewed all biopsy materials taken from the oral cavity in a single institution in Korea from 2012 to 2018 and found 4 cases of NS out of $726 .{ }^{5}$ The largest series of cases of NS in the year 1991 reported average age at the diagnosis as 45.9 years, Males outnumbered females by a ratio of 1.9: 1 , and whites outnumbered blacks by a ratio of 4.9:1. ${ }^{6}$ It may arise in any area containing salivary gland tissue. Classically, it involves the mucoserous glands of the hard palate. Other sites where it has been reported include nasal cavity, trachea, parotid gland, sublingual gland, submandibular gland, larynx, buccal mucosa, maxillary sinus, tongue, tonsil, and retromolar trigone. ${ }^{7}$ The etiology of this lesion is bizarre and controversial. The most commonly proposed and generally accepted etiology for NSM relates to ischemia. ${ }^{6}$ Other traumatic injuries, such as dental injection, blunt force trauma, denture wear, alcohol and tobacco use, as well as upper respiratory infections, have been implicated as potential predisposing factors. ${ }^{7}$ The exact pathophysiology of necrotizing sialometaplasia is unknown, but ischemia of the vasculature supplying the salivary gland lobules is the most widely accepted theory. ${ }^{8}$ furthermore, two experimental studies were able to produce necrotizing sialometaplasia in submandibular and sublingual glands of rats by ligating the vasculature supplying these major salivary glands. ${ }^{9,10}$ This lesion clinically presents as a deep ulcer, The size may range from 0.7 to $5.0 \mathrm{~cm}$ (average $1.8 \mathrm{~cm}$ ) with sharply demarcated borders, often surrounded by an erythematous halo. The posterior hard palate is the most common site to be affected by NS and junction of the hard and soft palate being the second most common site. About two-thirds of the palatal lesions are unilateral; however, midline, bilateral synchronous and metachronus lesions do occur. ${ }^{11,12}$ the diagnosis of this lesion is based on the histological criteria proposed by Abrams et $\mathrm{al}^{1}$., 1973 - The presence of ischemic lobular necrosis of seromucous glands, squamous metaplasia of ducts and acini, preservation of intact lobular architecture despite necrosis and inflammation, and accumulation of necrotic de- bris in the adjacent lobules. ${ }^{1}$ The diagnosis is mainly based on the clinical features and histopathological analysis. Squamous cell carcinoma and mucoepidermoid carcinoma has been considered as the differential diagnosis in the previous literature. No specific treatment is required since lesion is self-limiting and heals within the 6 to 8 weeks. This selflimiting condition has not yet been reported in Nepal which led us to publish this rare entity.

\section{CASE HISTORY/EXAMINATION:}

A twenty-six-year-old man reported to the department of oral medicine and radiology with the chief complaint of wound in the mid-palatal region since 35 days (figure 1). The patient noticed the ulcer which was initially a pea-sized and gradually progressed to present size within the span of 15-20 days and then remained of the approximately same size. Patient had the significant history of cigarette smoking for 10 pack years, which contributed to the anxiousness about the lesion due to cancerophobia, Patient had no significant medical history and past dental history, apart from prescription of different antibiotics and analgesics by previous dentists which could not improve his condition. There was no significant history of trauma. extra oral examination was non-significant and intraoral examination revealed generalized black stains on the coronal surface of the teeth and a solitary ulcer in the mid palatal region of size roughly $2 \times 3$ in its greatest dimension. The margin of an ulcer appeared rolled, erythematous and was covered with the yellowish slough. The lesion 
was non indurated, slight tender on palpation. The regional lymph nodes were non palpable.

\section{DIFFERENTIAL DIAGNOSIS, INVESTIGATIONS AND TREATMENT}

A provisional diagnosis of malignant ulcer was given, and the differential diagnosis with necrotizing sialometaplasia was considered. The occlusal radiograph depicted normal bone architecture., Laboratory investigations were within normal limits. The patient was subjected to incisional biopsy using infiltration anesthesia. The histopathological examination revealed Fibrinoid necrosis with sheet of neutrophils (figure 2) and Few acini surrounded by dense neutrophilic infiltration are present in the left upper corner, Hyperplastic squamous epithelial lining present on the right lower corner (figure 3). The final diagnosis of necrotizing metaplasia was arrived at based on clinical examination and histopathological analysis. The patient was subjected to symptomatic treatment, debridement of lesion using normal saline was made. The patient was assured of the lesion being of benign nature and as tobacco being one of the causes, tobacco cessation counselling was also done.

\section{OUTCOME AND FOLLOW-UP}

The lesion had completely healed post 15 days of the treatment. The patient is under regular follow up.

\section{DISCUSSION:}

As the title says, this is the self-limiting condition, and in our patient the lesion healed within a span of 15 days. This posed us a diagnostic dilemma, since the patient was young, presented with the rapid onset of the ulceration with the positive history of exposure to carcinogenic products, was initially diagnosed as malignant ulcer. as a part of an investigation, an incisional biopsy was done which was surprisingly Necrotizing sialometaplasia. This condition would have been considered as a differential diagnosis due to following factors such as typical location of its occurrence in the hard palate, gender of the patient and smoking being one of the predisposing factor. However, we missed out this lesion in the initial diagnosis probably because of its rarity, and not so prevalent in our country Nepal. This lesion was challenging for us during histopathological slide analysis since most of the features mimicked a malignancy. The careful examination of the histopathological features by an experienced pathologist led us to the correct diagnosis. Prior knowledge of the lesion and its features is very important to every clinician and every oral physician and oral pathologist so that misdiagnosis does not occur. After going through the literature based on this lesion, most of the case reports has reported this lesion in palatal region, and very rarely in other location. The typical characteristics of this lesion is presence of an ulceration with slough. Smoking can be considered as a probable etiological factor in this case since this is considered one among the etiology. However exact etiopathogenesis of how smoking causes necrotizing sialometaplasia has not yet been studied. Patient was subjected to routine laboratory investigation to rule out other conditions. Histopathological analysis using $\mathrm{H} \& \mathrm{E}$ staining is still considered as a gold standard, similarly done in our case. However, Rizkalla et al in his study used immunohistochemistry for identification of myoepithelial cells and CK7 expression which may help to distinguish NSM from its mimics. ${ }^{13}$ this lesion usually does not require any specific treatment, however symptomatic and conservative management is required.

\section{ACKNOWLEDGMENTS}

No acknowledgments are made.

\section{CONFLICT OF INTEREST}

The authors declare that there is no conflict of interests regarding the publication of this paper.

\section{AUTHORSHIP LIST:}

Author Contributions:

Author 1: Clinical Diagnosis and selection of case. Literature Search done, Edited and reviewed the manuscript. 
Author 2: Provided with the histopathological interpretations and photomicrograph. Edited and

reviewed the manuscript

Author 3: Written the manuscript at initial phase. Edited and reviewed the manuscript.

Author 4 and 5: edited and reviewed the manuscript for final manuscript preparation.

\section{REFERENCES:}

1. Abrams AM, Melrose RJ, Howell FV. Necrotizing sialometaplasia. A disease simulating malignancy. Cancer. $1973 \mathrm{Jul} ; 32(1): 130-5$.

2. Glick M. Burket's oral medicine. $12^{\text {th }}$ edition. PMPH USA; 2015.

3. Rajendran R. Shafer's textbook of oral pathology. Elsevier India; 2009.

4. Mesa ML, Gertler RS, Schneider LC. Necrotizing sialometaplasia: frequency of histologic misdiagnosis. Oral Surg Oral Med Oral Pathol. 1984 Jan;57(1):71-3

5. Shin SA, Na HY, Choe JY, Hong SN, Lee H, Park S, Kim JE. Necrotizing sialometaplasia: a malignant masquerade but questionable precancerous lesion, report of four cases. BMC Oral Health. 2020 Dec;20(1):1-6.

6. Brannon RB, Fowler CB, Hartman KS. Necrotizing sialometaplasia: a clinicopathologic study of sixty-nine cases and review of the literature. Oral surgery, oral medicine, oral pathology. 1991 Sep 1;72(3):317-25.

7. Carlson DL. Necrotizing sialometaplasia: a practical approach to the diagnosis. Archives of pathology \& laboratory medicine. 2009 May;133(5):692-8.

8. Imbery TA, Edwards PA. Necrotizing sialometaplasia: literature review and case reports. The Journal of the American Dental Association. 1996 Jul 1;127(7):1087-92.

9. Standish SM, Shafer WG. Several histologic effects of rat submaxillary and sublingual salivary gland duct and blood vessel ligation. J Dent Res 1957;36:866-79.

10. Englander A, Cataldo E. Experimental carcinogenesis in duct-artery ligated rat submandibular gland. J Dent Res 1976;55:229-34.

11. Zhurakivska K, Maiorano E, Nocini R, Mignogna MD, Favia G, Troiano G, Arena C, Caponio VC, Lo Muzio L. Necrotizing sialometaplasia can hide the presence of salivary gland tumors: A case series. Oral Diseases. 2019 May;25(4):1084-90.

12. Joshi SA, Halli R, Koranne V, Singh S. Necrotizing sialometaplasia: A diagnostic dilemma!. Journal of oral and maxillofacial pathology: JOMFP. 2014 Sep;18(3):420.

13. Rizkalla H, Toner M. Necrotizing sialometaplasia versus invasive carcinoma of the head and neck: the use of myoepithelial markers and keratin subtypes as an adjunct to diagnosis. Histopathology. 2007 Aug;51(2):184-9.

\section{List of figure captions/legends}

1. Figure 1 : intraoral view depicting the ulceration of the palatal region

2. Figure 2: Fibrinoid necrosis with sheet of neutrophils

3. Figure 3: Few acini surrounded by dense neutrophilic infiltration are present in the left upper corner, Hyperplastic squamous epithelial lining present on the right lower corner. 

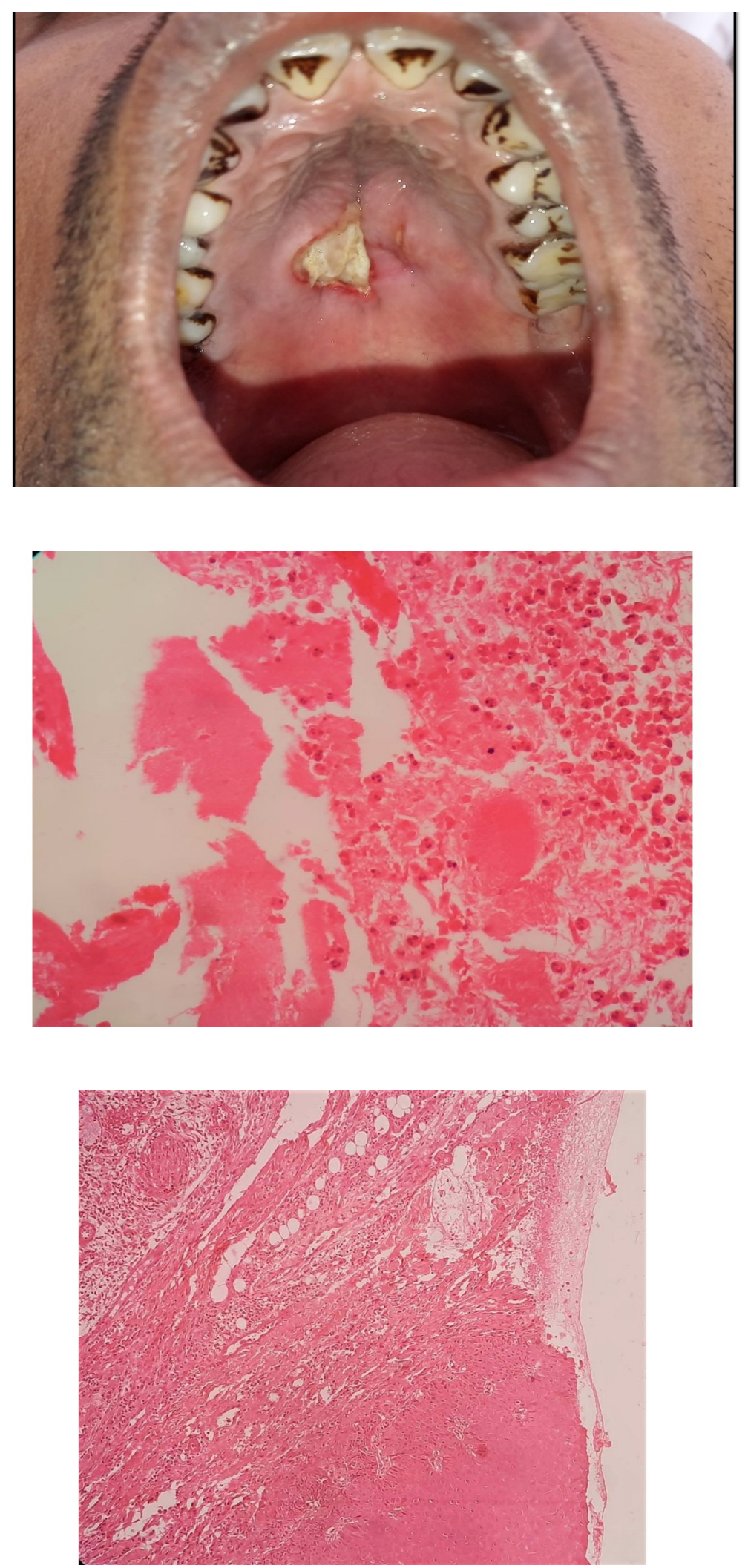